\title{
Remission of screen-detected metabolic syndrome and its determinants: an observational study
}

\author{
Corine den Engelsen ${ }^{1 *}$, Kees J Gorter ${ }^{1}$, Philippe L Salomé ${ }^{2}$, Maureen van den Donk ${ }^{1}$ and Guy E Rutten ${ }^{1}$
}

\begin{abstract}
Background: Early detection and treatment of the metabolic syndrome may prevent diabetes and cardiovascular disease. Our aim was to assess remission of the metabolic syndrome and its determinants after a population based screening without predefined intervention in the Netherlands.

Methods: In 2006 we detected 406 metabolic syndrome cases (The National Cholesterol Education Program's Adult Treatment Panel III (NCEP ATP III) definition) among apparently healthy individuals with an increased waist circumference. They received usual care in a primary care setting. After three years metabolic syndrome status was re-measured. We evaluated which baseline determinants were independently associated with remission.

Results: The remission rate among the 194 participants was 53\%. Baseline determinants independently associated with a remission were the presence of more than three metabolic syndrome components (OR 0.46) and higher levels of waist circumference (OR 0.91), blood pressure (OR 0.98) and fasting glucose (OR 0.60).

Conclusions: In a population with screen-detected metabolic syndrome receiving usual care, more than half of the participants achieved a remission after three years. This positive result after a relatively simple strategy provides a solid basis for a nation-wide implementation. Not so much socio-demographic variables but a higher number and level of the metabolic syndrome components were predictors of a lower chance of remission. In such cases, primary care physicians should be extra alert.
\end{abstract}

Keywords: Metabolic syndrome, Abdominal obesity, Screening, Cardiovascular risk, Primary care

\section{Background}

The term 'Metabolic Syndrome' (MetS) refers to a clustering of cardiovascular risk factors, which is clinically relevant to identify people with a high cardiovascular risk. People with MetS have an increased risk of developing both type 2 diabetes and cardiovascular disease [1-4] and an up to fourfold increased risk of mortality from cardiovascular disease [2,3]. Early detection and adequate treatment can modify or even abolish the risk factors and thus prevent cardiovascular disease [5-8]. Identifying people who are less likely to achieve a remission is important, in order to give them more attention

\footnotetext{
* Correspondence: c.denengelsen-2@umcutrecht.nl

'Julius Center for Health Sciences and Primary Care, University Medical Center Utrecht, Huispostnr STR.6.131, P.O. Box 85500, 3508 GA, Utrecht, Netherlands

Full list of author information is available at the end of the article
}

and to intensify their treatment. Several studies assessed remission of the MetS, all following a structured intervention. Such interventions are usually not in accordance with daily practice. Especially interventions performed in a randomized controlled trial setting often provide data in a clinical context that does not exist outside the trial itself, thereby limiting generalizability [9]. The more a follow-up trajectory fits in daily practice, the better a screening strategy can be implemented. However, data on remission of the MetS following usual care are scarce. The same applies to prognostic determinants for remission.

Our aim was to assess the remission of the MetS in individuals with screen-detected MetS and to determine which determinants at the time of diagnosis predict remission three years after screening, followed by usual care in a primary care setting.

\section{Biomed Central}

(c) 2012 den Engelsen et al.; licensee BioMed Central Ltd. This is an Open Access article distributed under the terms of the Creative Commons Attribution License (http://creativecommons.org/licenses/by/2.0), which permits unrestricted use, distribution, and reproduction in any medium, provided the original work is properly cited. 


\section{Methods}

\section{Study design and population}

Between October 2006 and April 2007 the 'IJsselstein Screening for Central Obesity to detect metabolic syndrome' was conducted in the city of IJsselstein among 12.000 individuals. The aim was to determine the feasibility and yield of a screening for MetS with self-measurement of waist circumference as the first step [10]. A total of 1.721 individuals with a selfmeasured increased waist circumference $(\geq 88 \mathrm{~cm}$ in women, $\geq 102 \mathrm{~cm}$ in men) underwent all study procedures. They were aged 20-70 years and not previously diagnosed with diabetes, hypertension, dyslipidemia or cardiovascular disease. 473 of them were detected with MetS. Participants were advised to contact their primary care center for the results of the screening; no other intervention was performed. In case of detected cardiovascular risk factors, they should receive usual care according to the guidelines 'Cardiovascular risk management' [11] and 'Type 2 Diabetes Mellitus' [12] of the Dutch College of General Practitioners. Follow-up measurements took place three years after screening, in November and December 2009. 406 of the 473 participants with screen-detected MetS were invited for follow-up measurements. The other 67 were no longer eligible because of illness and death or because they were no longer visiting the same primary care physician. Three and six weeks after the invitation, reminders were sent to the non-responders.

The study was approved by the medical ethics committee of the University Medical Center Utrecht, the Netherlands. Written informed consent was obtained from all participants.

\section{Measurements}

Both at screening and three years later at follow-up the same measurements were performed. In a physical examination body weight, height, waist circumference and blood pressure were measured. Venous blood samples were drawn after an overnight fast to determine fasting blood glucose, triglycerides and high-density lipoprotein (HDL) cholesterol. A detailed description of these measurements was described previously [10].

At baseline participants had completed a questionnaire to determine ethnicity, education level and lifestyle factors (smoking habits, physical activity). Education level was dichotomized, in which 'high' was defined as having completed a level of secondary education which permits entry to college. Smoking was regarded positive when the participant was currently smoking; in case of former or never smoking it was regarded negative. Physical activity was assessed using the validated SQUASH questionnaire [13], which measures habitual activities with respect to occupation, leisure time, household, transportation means, and other daily activities. The results were dichotomized based on the Dutch Standard Healthy Movement: a minimum of thirty minutes of moderately intensive exercise at least five days a week [14].

At follow-up, smoking status and level of physical activity were re-evaluated using the same questionnaire, in which participants were also questioned about consulting a dietician. Data about prescribed cardiovascular medication at the time of follow-up were collected from the physician's electronic medical record. As a measure of follow-up behavior we used the number of visits to the practice nurse during the first year following screening, collected from the electronic medical record.

\section{Outcome measure}

The MetS was defined according to The National Cholesterol Education Program's Adult Treatment Panel III (NCEP ATP III) criteria, namely the presence of at least three of the following five components: increased waist circumference $(\geq 88 \mathrm{~cm}$ in women, $\geq 102 \mathrm{~cm}$ in men), elevated blood pressure (systolic $\geq 130$ and/or diastolic $\geq 85 \mathrm{mmHg}$ ), elevated triglycerides $(\geq 1.7 \mathrm{mmol} / \mathrm{L})$, elevated fasting glucose $(\geq 6.1 \mathrm{mmol} / \mathrm{L})$, and reduced HDL cholesterol $(<1.0 \mathrm{mmol} / \mathrm{L}$ in men, $<1.3 \mathrm{mmol} / \mathrm{L}$ in women) [15]. We defined remission as having less than three MetS components at follow-up, thereby no longer fulfilling the criteria for the presence of the MetS. We did not take the use of cardiovascular medication into account in the definition of remission.

\section{Determinants}

Both socio-demographic and clinical characteristics were considered as potential baseline determinants of remission. We considered several determinants with regard to the follow-up period as potential confounders (consultation behavior, weight loss, change in level of physical activity and prescription of cardiovascular medication for a specific MetS component).

\section{Data analysis}

Categorical variables are reported as numbers and percentages, continuous variables as means with standard deviations (SD) and non-normally distributed variables as median with interquartile range.

We checked for selection bias by testing for differences in baseline variables (gender, age, body mass index (BMI), waist circumference, HDL cholesterol, fasting glucose, triglycerides and blood pressure) between responders and non-responders, and between participants (responders willing to participate) and non-participants (responders who indicated not to be interested in followup measurements). Chi-square tests were used for categorical variables, independent samples t-tests for 
normally distributed continuous variables and MannWhitney tests for non-normally distributed continuous variables. The same tests were used to test for baseline differences between participants who achieved a remission and those who did not. Paired samples t-tests for normally distributed variables and the Wilcoxon signedrank test for non-normally distributed variables were used to test for a significant change in mean risk factor levels between screening and follow-up. A p-value $<0.05$ was considered significant.

For logistic regression analyses, triglyceride level was $\log$ transformed because of its skewed distribution. Waist circumference and HDL cholesterol were also transformed, taking into account the gender specific thresholds. The gender specific threshold was extracted from the values obtained in the examinations. The new variables indicate the absolute difference with the gender specific threshold.

Univariable and multivariable logistic regression analyses were performed to assess determinants of remission. All variables considered as potential baseline determinants (Table 3) were entered into model 1, except for BMI, because of the high correlation with waist circumference. In model 2 the follow-up determinants were included as co-variables. The models were reduced by means of backward selection, based on the p-value of the Wald test. The variables with the highest $\mathrm{p}$-value were one by one removed, until the p-value for each variable became $<0.20$. All MetS components as well as gender were kept in the model, regardless of their p-value. Analyses were performed using Statistical Package of Social Sciences (SPSS, version 17.0).

\section{Results}

The response rate was $86 \%$. 194 responders were willing to participate in follow-up examinations. The study flow chart is shown in Figure 1. $53.6 \%$ of the participants were male and the mean age was 49.0 years (SD 10.1). Baseline characteristics are shown in Table 1.

Comparing the participants with the combined group of non-participants and non-responders showed that participants were older (49 versus 46 years, $\mathrm{p}<0.01$ ) and more often visited the practice nurse at least twice in the year following screening (69 versus $56 \%$, $\mathrm{p}<0.01)$. Non-responders were significantly younger than responders ( 40 versus 49 years, $\mathrm{p}<0.001$ ) and more often of non-Western European origin (15 versus $4 \%$, $\mathrm{p}<0.01)$ whereas responders more often than nonresponders achieved the Dutch Standard Healthy Movement (42 versus $58 \%, \mathrm{p}=0.03$ ) and more often visited the practice nurse at least twice (65 versus $47 \%$, $\mathrm{p}=0.01)$. Participants more often had a higher education level (35 versus $27 \%, \mathrm{p}<0.05)$ than non-participants. However, they less often achieved the Dutch Standard Healthy Movement at baseline compared to nonparticipants (53 versus $64 \%, \mathrm{p}=0.03$ ).

Three years after screening a significant improvement in almost all MetS components was observed. However,

Table 1 Baseline characteristics of the population with screen-detected metabolic syndrome participating in follow-up measurements, divided into those who did and did not achieve a remission

\begin{tabular}{|c|c|c|c|c|c|}
\hline \multirow[t]{2}{*}{ Baseline characteristics } & & \multirow{2}{*}{$\frac{\text { Total group }}{n=194}$} & \multicolumn{2}{|l|}{ Remission } & \multirow[t]{2}{*}{ P-value } \\
\hline & & & Yes $n=103$ & No $n=91$ & \\
\hline Gender (\% male) & & $104(53.9)$ & $53(51.5)$ & $51(56.0)$ & 0.52 \\
\hline Age (years) & & $49.0 \pm 10.1$ & $48.2 \pm 10.9$ & $49.8 \pm 9.0$ & 0.27 \\
\hline Ethnicity (\% Western European) & & $187(96.4)$ & $100(97.1)$ & $87(95.6)$ & 0.58 \\
\hline Higher educated (\%) & & $68(35.1)$ & 37 (35.9) & $31(34.1)$ & 0.79 \\
\hline Smoking (\%) & & $43(22.2)$ & $22(21.4)$ & $21(23.1)$ & 0.77 \\
\hline $\begin{array}{l}\text { Physical activity (\% adhering to Dutch } \\
\text { Standard Healthy Movement }{ }^{a} \text { ) }\end{array}$ & & $102(53.4)$ & $52(51.5)$ & $49(53.8)$ & 0.74 \\
\hline $\operatorname{BMI}\left(\mathrm{kg} / \mathrm{m}^{2}\right)$ & & $30.1 \pm 3.7$ & $29.7 \pm 3.5$ & $30.7 \pm 3.8$ & $<0.05$ \\
\hline \multirow[t]{2}{*}{ Waist circumference $(\mathrm{cm})$} & $\hat{\sigma}$ & $109.9 \pm 7.4$ & $106.6 \pm 5.5$ & $113.3 \pm 7.6$ & $<0.001$ \\
\hline & q & $99.5 \pm 8.8$ & $98.4 \pm 8.9$ & $101.0 \pm 8.7$ & 0.18 \\
\hline \multirow[t]{2}{*}{ Blood pressure $(\mathrm{mmHg})$} & Systolic & $143.5 \pm 14.9$ & $142.0 \pm 12.5$ & $145.3 \pm 17.2$ & 0.14 \\
\hline & Diastolic & $88.0 \pm 7.5$ & $87.1 \pm 7.3$ & $89.1 \pm 7.6$ & 0.07 \\
\hline Triglycerides (mmol/L) & & $1.9(1.6-2.3)$ & $1.9(1.6-2.3)$ & $1.9(1.7-2.5)$ & 0.24 \\
\hline \multirow[t]{2}{*}{ HDL cholesterol (mmol/L) } & $\hat{\sigma}$ & $1.1 \pm 0.3$ & $1.1 \pm 0.3$ & $1.1 \pm 0.2$ & 0.44 \\
\hline & q & $1.3 \pm 0.3$ & $1.4 \pm 0.3$ & $1.3 \pm 0.3$ & 0.04 \\
\hline Fasting glucose (mmol/L) & & $5.3 \pm 1.1$ & $5.0 \pm 0.6$ & $5.5 \pm 1.5$ & 0.01 \\
\hline
\end{tabular}

Data are reported as means \pm standard deviation or number (percentage). Non-normally distributed variables are reported as median $\left(25^{\text {th }}-75^{\text {th }}\right.$ percentile).

a a minimum of thirty minutes of moderately intensive exercise at least five days a week. 


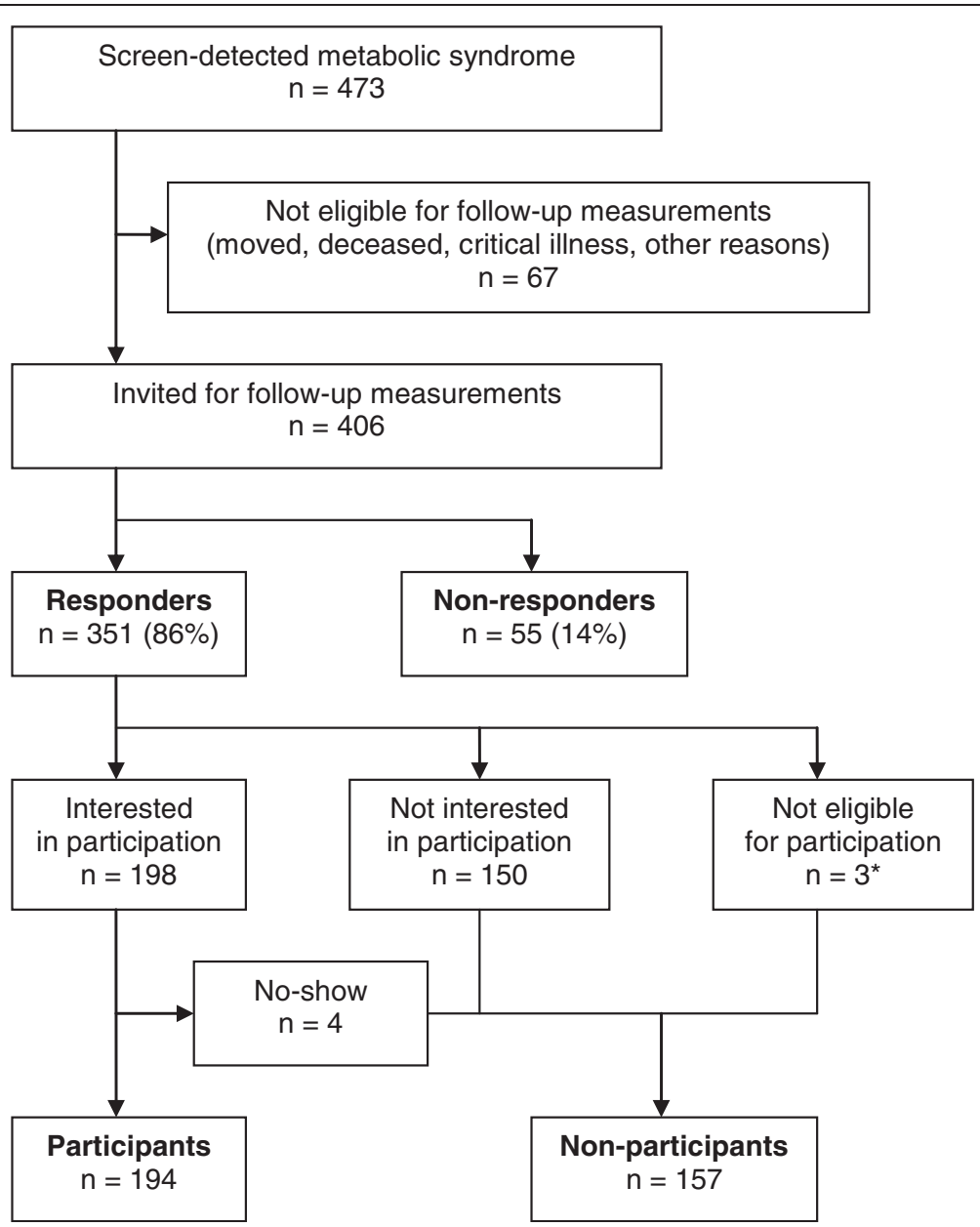

Figure 1 Study flowchart. Legend: * Reasons for exclusion: pregnancy $(n=1)$, illness $(n=1)$, stay abroad $(n=1)$.

the mean glucose level increased in both people with and without a remission of the MetS (Table 2). Of the 194 participants diagnosed with MetS, 103 (53.1\%) no longer fulfilled the MetS criteria according to their follow-up levels of the components. The participants who still fulfilled the MetS criteria at follow-up had a higher BMI and fasting glucose at baseline. Men not achieving a remission had a higher waist circumference, whereas women not achieving a remission had a significantly lower HDL cholesterol level at baseline (Table 1).

At follow-up, 57 (29.4\%) participants received antihypertensive medication, $55(28.4 \%)$ received a statin and eight $(4.1 \%)$ were on blood glucose lowering medication. Fibrates or nicotinic acid were not prescribed. In $132(68.0 \%)$ participants, no medication for a specific MetS component was prescribed.

The presence of more than three MetS components and a higher waist circumference and fasting glucose were the baseline determinants significantly associated with a lower chance of remission in univariable regression analysis (Table 3).
The odds ratios for the variables that were independently associated with remission $(\mathrm{p}<0.20)$ are shown in Table 4. When evaluating only baseline determinants, age, a higher waist circumference and glucose, a lower HDL cholesterol and the presence of more than three MetS components were independently associated with a lower chance of remission. When adding follow-up determinants as co-variables, age and HDL cholesterol no longer showed an independent association with remission, whereas weight loss during follow-up did. Each kilogram of weight loss increased the likelihood of achieving a remission 1.2 times.

\section{Discussion}

We performed a screening in primary care among apparently healthy individuals, to detect new MetS cases. Participants were only advised to contact their primary care center for the results of the screening. Upon contacting they were expected to receive usual care according to existing guidelines; no specific intervention was designed. More than half of the participants 
Table 2 Mean risk factor levels and mean change from baseline

\begin{tabular}{llllll}
\hline $\mathbf{n = 1 9 4}$ & & $\mathbf{2 0 0 6}$ & $\mathbf{2 0 0 9}$ & Mean change from baseline & $\mathbf{( 9 5} \%$ C.I.) \\
\hline Weight $(\mathrm{kg})$ & & $93.1 \pm 15.2$ & $90.6 \pm 16.1$ & $-2.5 \pm 6.4$ & $(-3.4 ;-1.6)$ \\
BMI $\left(\mathrm{kg} / \mathrm{m}^{2}\right)$ & $30.1 \pm 3.7$ & $29.2 \pm 4.1$ & $-0.9 \pm 2.0$ & $(-1.2 ;-0.6)$ \\
Waist circumference $(\mathrm{cm})$ & 0 & $109.9 \pm 7.4$ & $106.2 \pm 9.4$ & $-3.6 \pm 6.4$ & $(-4.9 ;-2.4)$ \\
& + & $99.5 \pm 8.8$ & $95.9 \pm 10.7$ & $-3.6 \pm 6.9$ & $(-5.1 ;-2.1)$ \\
Blood pressure $(\mathrm{mmHg})$ & Systolic & $143.5 \pm 14.9$ & $135.4 \pm 13.6$ & $-8.1 \pm 12.1$ & $(-9.8 ;-6.4)$ \\
& Diastolic & $88.0 \pm 7.5$ & $82.4 \pm 7.7$ & $-5.6 \pm 7.7$ & $(-6.7 ;-4.5)$ \\
Triglycerides $(\mathrm{mmol} / \mathrm{L})$ & & $1.9(1.6-2.3)$ & $1.8(1.3-2.3)$ & $-0.3 \pm 1.1$ & $(-0.4 ;-0.1)$ \\
HDL cholesterol $(\mathrm{mmol} / \mathrm{L})$ & 0 & $1.1 \pm 0.3$ & $1.2 \pm 0.3$ & $0.1 \pm 0.1$ & $(0.03 ; 0.08)$ \\
& + & $1.3 \pm 0.3$ & $1.4 \pm 0.3$ & $0.2 \pm 0.2$ & $(0.05 ; 0.14)$ \\
Fasting glucose $(\mathrm{mmol} / \mathrm{L})$ & & $5.3 \pm 1.1$ & $5.4 \pm 0.7$ & $0.2 \pm 0.9$ & $(0.0 ; 0.3)$ \\
\hline
\end{tabular}

Data are reported as means \pm standard deviation or percentage. Non-normally distributed variables are reported as median $\left(25^{\text {th }}-75^{\text {th }}\right.$ percentile).

Table 3 Associations of potential determinants with remission in univariable logistic regression analysis

\begin{tabular}{|c|c|c|c|c|c|c|}
\hline & & n (\%) & $\begin{array}{l}\text { Remission } \\
\text { rate (\%) }\end{array}$ & $O R^{a}$ & (95 \% C.I.) & P-value \\
\hline \multicolumn{7}{|l|}{ Baseline determinants } \\
\hline Age (years) & & & & 0.98 & $(0.95 ; 1.01)$ & 0.27 \\
\hline \multirow[t]{2}{*}{ Gender } & $\hat{0}$ & $104(53.6)$ & 51.0 & Ref. & & \\
\hline & q & $90(46.4)$ & 55.6 & 1.20 & $(0.68 ; 2.12)$ & 0.52 \\
\hline \multirow[t]{2}{*}{ Ethnicity } & Western European & $187(96.4)$ & 53.5 & Ref. & & \\
\hline & Other & 7 (3.6) & 42.9 & 0.65 & $(0.14 ; 3.00)$ & 0.58 \\
\hline \multirow[t]{2}{*}{ Higher educated } & No & $126(64.9)$ & 52.4 & Ref. & & \\
\hline & Yes & $68(35.1)$ & 54.4 & 1.09 & $(0.60 ; 1.96)$ & 0.79 \\
\hline \multirow[t]{2}{*}{ Smoking } & No & $151(77.8)$ & 53.6 & Ref. & & \\
\hline & Yes & $43(22.2)$ & 51.2 & 0.91 & $(0.46 ; 1.78)$ & 0.77 \\
\hline \multirow[t]{2}{*}{ Number of metabolic syndrome components } & 3 & $149(76.8)$ & 59.7 & Ref. & & \\
\hline & $\geq 4$ & $45(23.2)$ & 31.1 & 0.30 & $(0.15 ; 0.62)$ & $<0.01$ \\
\hline $\mathrm{BMI}\left(\mathrm{kg} / \mathrm{m}^{2}\right)$ & & & & 0.92 & $(0.85 ; 1.00)$ & 0.05 \\
\hline HDL cholesterol (mmol/L) & & & & 2.64 & $(0.97 ; 7.18)$ & 0.06 \\
\hline Waist circumference $(\mathrm{cm})$ & & & & 0.93 & $(0.89 ; 0.97)$ & $<0.001$ \\
\hline \multirow[t]{2}{*}{ Blood pressure (mmHg) } & Systolic & & & 0.99 & $(0.97 ; 1.01)$ & 0.14 \\
\hline & Diastolic & & & 0.96 & $(0.93 ; 1.00)$ & 0.07 \\
\hline Triglycerides (mmol/L) & & & & 0.57 & $(0.29 ; 1.11)$ & 0.10 \\
\hline Fasting glucose (mmol/L) & & & & 0.55 & $(0.36 ; 0.85)$ & $<0.01$ \\
\hline \multicolumn{7}{|l|}{ Follow-up determinants } \\
\hline \multirow[t]{2}{*}{$\geq 2$ consultations with practice nurse } & No & $60(30.9)$ & 51.7 & Ref. & & \\
\hline & Yes & $134(69.1)$ & 53.7 & 1.09 & $(0.59 ; 2.00)$ & 0.07 \\
\hline \multirow{2}{*}{$\begin{array}{l}\text { Cardiovascular medication, specific for } \\
\text { metabolic syndrome component }\end{array}$} & No & $132(68.0)$ & 56.1 & Ref. & & \\
\hline & Yes & $62(32.0)$ & 46.8 & 0.69 & $(0.38 ; 1.26)$ & 0.23 \\
\hline \multirow[t]{2}{*}{ Consultation with dietician } & No & $133(68.6)$ & 55.6 & Ref. & & \\
\hline & Yes & $61(31.4)$ & 47.5 & 0.72 & $(0.39 ; 1.33)$ & 0.30 \\
\hline Change in physical activity level (hours/week) & & & & 1.00 & $(0.98 ; 1.01)$ & 0.48 \\
\hline Weight loss (kg) & & & & 1.14 & $(1.07 ; 1.20)$ & $<0.001$ \\
\hline
\end{tabular}

${ }^{a}$ Odds ratio per one-unit change. 
Table 4 Determinants independently associated $(p<0.20)$ with remission in multivariable logistic regression analysis

\begin{tabular}{|c|c|c|c|c|c|c|c|c|c|c|}
\hline & & & Mode & & & & & Mode & & \\
\hline & $\overline{\mathrm{OR}^{\mathrm{a}}}$ & (95 \% C.I.) & $\mathrm{OR}^{\mathrm{b}}$ & (95 \% C.I.) & P-value & $\overline{\mathrm{OR}^{\mathrm{a}}}$ & (95 \% C.I.) & $\mathrm{OR}^{\mathrm{b}}$ & (95 \% C.I.) & P-value \\
\hline Age (years) & 0.98 & $(0.94 ; 1.01)$ & & & 0.18 & & & & & \\
\hline Gender (female) & 1.37 & $(0.69 ; 2.73)$ & & & 0.37 & 1.23 & $(0.58 ; 2.61)$ & & & 0.59 \\
\hline Waist circumference (cm) & 0.93 & $(0.89 ; 0.97)$ & 0.56 & $(0.39 ; 0.81)$ & $<0.01$ & 0.91 & $(0.87 ; 0.96)$ & 0.46 & $(0.30 ; 0.71)$ & $<0.01$ \\
\hline HDL cholesterol (mmol/L) & 2.52 & $(0.73 ; 8.69)$ & 1.31 & $(0.91 ; 1.90)$ & 0.14 & 1.69 & $(0.48 ; 5.89)$ & 1.17 & $(0.81 ; 1.69)$ & 0.41 \\
\hline Fasting glucose (mmol/L) & 0.68 & $(0.43 ; 1.10)$ & 0.65 & $(0.38 ; 1.11)$ & 0.11 & 0.60 & $(0.36 ; 1.00)$ & 0.56 & $(0.31 ; 1.00)$ & 0.05 \\
\hline Triglycerides (mmol/L) & 0.94 & $(0.41 ; 2.16)$ & 0.97 & $(0.68 ; 1.40)$ & 0.88 & 0.64 & $(0.27 ; 1.55)$ & 0.82 & $(0.56 ; 1.21)$ & 0.32 \\
\hline Systolic blood pressure $(\mathrm{mmHg})$ & 0.99 & $(0.97 ; 1.01)$ & 0.84 & $(0.60 ; 1.18)$ & 0.32 & 0.98 & $(0.95 ; 1.00)$ & 0.70 & $(0.49 ; 1.01)$ & 0.05 \\
\hline$\geq 4$ metabolic syndrome components & 0.48 & $(0.20 ; 1.13)$ & & & 0.09 & 0.46 & $(0.18 ; 1.19)$ & & & 0.11 \\
\hline Weight loss (kg) & & & & & & 1.18 & $(1.10 ; 1.27)$ & & & $<0.001$ \\
\hline
\end{tabular}

Model 1: only baseline determinants were entered into the model. The metabolic syndrome components and gender were kept in the model, regardless of their p-value.

Model 2: both baseline and follow-up determinants were entered into the model. The metabolic syndrome components and gender were kept in the model, regardless of their $\mathrm{p}$-value.

a Odds ratio per one-unit change.

${ }^{\mathrm{b}}$ Odds ratio per standard deviation increase.

detected with MetS at screening no longer fulfilled the metabolic syndrome criteria three years later. The presence of more than three MetS components and a higher waist circumference, glucose level and systolic blood pressure were independently associated with a lower chance of remission.

Several studies have assessed the remission of MetS, all after an intervention. These interventions include diet (remission rate 21-61 \%) [16-18], exercise programs (remission rate 42-58 \%) [19,20], combinations of both (remission rate $67 \%$ ) [21], bariatric surgery (remission rate up to $95 \%$ ) [22-24] and medication such as metformin, fenofibrate and orlistat (remission rate 23-44\%) $[25,26]$. However, data about remission of the MetS without predefined intervention unless the advice to contact the primary care center are scarce. Two randomized controlled trials reported remission rates for their control groups of 9 and $18 \%$ [26,27]. Our higher remission rate might be explained by the intensity of our usual care, which was presumably higher than control group care as described by Orchard et al. and Bo et al. In these studies participants received lifestyle recommendations once, while the majority of our participants was seen several times by the practice nurse. The remission rate of $52 \%$ observed in a prospective study more closely resembled our remission rate, which could be explained by an intervention more in agreement with our usual care [28]. However the follow-up period was only six months; it is uncertain what would have happened after this relatively short intervention period.

In our study, not only individuals with diabetes or cardiovascular disease were excluded. Individuals were only eligible for screening if they were not previously diagnosed with hypertension or dyslipidemia and did not use antihypertensive, blood glucose lowering or cholesterol lowering medication: they were apparently healthy. The shock of suddenly being diagnosed with several risk factors might have been an extra impulse to change lifestyle, which might have contributed to the high remission rate. Two studies compared baseline characteristics between participants who did and did not achieve a remission $[17,19]$. As in our study, the participants who did not achieve a remission had worse baseline values than the participants who did achieve a remission. This might be explained by the fact that achieving a remission is more difficult for participants with higher risk factor levels. Baseline HDL cholesterol level was not associated with remission, in contrast to baseline levels of glucose, waist circumference and systolic blood pressure, where lower baseline levels were associated with a higher chance of remission. HDL dysfunction could be an underlying reason for the absence of an association between baseline HDL cholesterol level and remission. Dysfunctional HDL particles lose their anti-inflammatory and atheroprotective properties. This condition is closely linked to obesity and to inflammation and might be more prevalent among people with high HDL concentrations. In Western populations, individuals with glucose intolerance or those at risk for cardiometabolic disease - people with MetS could be affected by impaired function of HDL $[29,30]$.

\section{Study limitations and strengths}

This is the first study assessing remission of MetS after screening among apparently healthy people, without a predefined intervention program. The follow-up period of three years provides us with intermediate-term results. A shorter follow-up period might give too optimistic remission rates, because treatment effects and 
lifestyle changes tend to level off over time. Both socioeconomic and demographic, biochemical and clinical variables were taken into account, as well as lifestyle factors. Our data on the prescription of cardiovascular medication were based on prescription according to the electronic medical record of the primary care physician. Actual use of the prescribed medication might be lower, since medication compliance, especially in primary prevention, is not optimal [31-33].

According to the NCEP ATP III criteria, when a patient is on drug treatment for a specific MetS component (antihypertensive drug treatment, blood glucose lowering treatment or treatment with a fibrate or nicotinic acid for a reduced HDL cholesterol or an increased triglyceride level) this component should be regarded as present, irrespective of the actual level of the component [15]. This means that for example the blood pressure component will be regarded as positive as long as someone is on antihypertensive drug treatment, despite perfect blood pressure levels and thereby a reduced cardiovascular risk. Therefore, to gain insight into the actual reduction in cardiovascular risk achieved by remission, we chose not to take drug treatment for a specific MetS component into our definition of remission. In fact, the definition of the MetS provides a good screening tool to detect people with a high cardiovascular risk, but the current NCEP ATP III definition is less suitable for evaluating the effect of an intervention on changes in risk. If we had taken prescription of medication for a specific MetS component into account in our definition our remission rate would have been $49.0 \%$.

The overall response rate was good, although a substantial amount of the responders indicated not to be interested in participating in follow-up. This resulted in a relatively small study population. One might assume that people willing to participate were the more motivated patients, leading to potential bias for the generalization of the results. Indeed the participants more often entered a follow-up regimen after screening than the nonparticipants and non-responders. Whether their higher motivation also has led to a higher remission rate is questionable. However, we have to take into account this potential bias in interpreting the results. Especially younger people were less interested in follow-up measurements. At the initial screening, it were also the younger subgroups in which an invitation reminder was necessary to get a sufficient response. Apparently first it takes more effort to involve younger people in screening, and then we gain less insight into the impact of the screening for their cardiovascular health. It would be interesting to know the remission rate among the younger non-participants, since half of the people detected with the MetS were younger than 50 years [10]. Age, however, was not significantly associated with achieving a remission in multivariable analysis.

\section{Conclusions}

Screening with self-measurement of waist circumference as a first step detected 473 MetS cases among apparently healthy people. Among those who were willing to participate in follow-up examinations, $53 \%$ no longer had the MetS after three years. This positive result after a relatively simple strategy provides a solid basis for a nationwide implementation. However, people $<50$ years seem less willing to participate in screening and follow-up, a finding that should be taken into account for future screening strategies. Not so much socio-demographic variables but a higher level of the MetS components and the presence of more than three components were baseline predictors of a lower chance of remission. In such cases, primary care physicians should be extra alert.

\section{Abbreviations}

Mets: Metabolic Syndrome; NCEP ATP III: The National Cholesterol Education Program's Adult Treatment Panel III; BMI: Body Mass Index; HDL: Cholesterol High-Density Lipoprotein Cholesterol.

\section{Competing interests}

The authors declare that they have no competing interests.

\section{Authors' contributions}

$\mathrm{CdE}$ researched the data, performed the statistical analyses and wrote the manuscript. KJG, PLS, MvdD and GER contributed to the discussion. All authors were involved in the design of the study and read and approved the final manuscript.

\section{Acknowledgements}

The IJsselstein Study of Central Obesity to detect metabolic syndrome was supported in part by a research grant from the Investigator Initiated Studies Program of Merck Sharp \& Dome Corp (MSD). MSD had no role in the study design and conduct, the writing of the manuscript or the decision to submit the paper for publication. The opinions expressed in this paper are those of the authors and do not necessarily represent those of MSD.

\section{Author details}

1 Julius Center for Health Sciences and Primary Care, University Medical Center Utrecht, Huispostnr STR.6.131, P.O. Box 85500, 3508 GA, Utrecht, Netherlands. ${ }^{2}$ Huisartsenzorg IJsselstein, locatie 't Steyn, Eiteren 15, 3401 PS IJsselstein, Netherlands.

Received: 30 January 2012 Accepted: 10 September 2012 Published: 13 September 2012

\section{References}

1. Ford ES, Schulze MB, Pischon T, Bergmann MM, Joost HG, Boeing H: Metabolic syndrome and risk of incident diabetes: findings from the European Prospective Investigation into Cancer and Nutrition-Potsdam Study. Cardiovasc Diabetol 2008, 7:35.

2. Galassi A, Reynolds K, He J: Metabolic syndrome and risk of cardiovascular disease: a meta-analysis. Am J Med 2006, 119:812-819.

3. Gami AS, Witt BJ, Howard DE, Erwin PJ, Gami LA, Somers VK, Montori VM: Metabolic syndrome and risk of incident cardiovascular events and death: a systematic review and meta-analysis of longitudinal studies. J Am Coll Cardiol 2007, 49:403-414.

4. Lorenzo C, Okoloise M, Williams K, Stern MP, Haffner SM: The metabolic syndrome as predictor of type 2 diabetes: the San Antonio heart study. Diabetes Care 2003, 26:3153-3159.

5. Hansson L, Lindholm LH, Niskanen L, Lanke J, Hedner T, Niklason A, Luomanmaki K, Dahlof B, Morlin C, Karlberg BE, Wester PO, Bjorck JE, De FU: JE: Effect of angiotensin-converting-enzyme inhibition compared with conventional therapy on cardiovascular morbidity and mortality in hypertension: the Captopril Prevention Project (CAPPP) randomised trial. Lancet 1999, 353:611-616. 
6. Hansson L, Hedner T, Lund-Johansen P, Kjeldsen SE, Lindholm LH, Syvertsen JO, Lanke J, De FU, Dahlof B, Karlberg BE: Randomised trial of effects of calcium antagonists compared with diuretics and beta-blockers on cardiovascular morbidity and mortality in hypertension: the Nordic Diltiazem (NORDIL) study. Lancet 2000, 356:359-365.

7. UK Prospective Diabetes Study (UKPDS) Group: Effect of intensive bloodglucose control with metformin on complications in overweight patients with type 2 diabetes (UKPDS 34). Lancet 1998, 352:854-865.

8. Wong ND, Pio JR, Franklin SS, L'Italien GJ, Kamath TV, Williams GR: Preventing coronary events by optimal control of blood pressure and lipids in patients with the metabolic syndrome. Am J Cardiol 2003, 91:1421-1426.

9. Bagshaw SM, Bellomo R: The need to reform our assessment of evidence from clinical trials: a commentary. Philos Ethics Humanit Med 2008, $3: 23$.

10. Van den Donk M, Bobbink IWG, Gorter KJ, Salomé PL, Rutten GEHM: Identifying people with metabolic syndrome in primary care by screening with a mailed tape measure. A survey in 14,000 people in the Netherlands. Prev Med 2009, 48:345-350.

11. Stalman WA, Scheltens T, Burgers JS, Hukkelhoven CW, Smorenburg SM, Banga JD, Dippel DW: NHG-Standaard Cardiovasculair risicomanagement. Houten: Bohn Stafleu van Loghum; 2006.

12. Rutten GEHM, De Grauw WJC, Nijpels G, Goudswaard AN, Uitewaal PJM, Van der Does FEE, Heine RJ, Van Ballegooie E, Verduijn MM, Bouma M: NHGStandaard Diabetes mellitus type 2 (Tweede herziening). Huisarts en Wetenschap 2006, 49:137-52

13. Wendel-Vos GC, Schuit AJ, Saris WH, Kromhout D: Reproducibility and relative validity of the short questionnaire to assess health-enhancing physical activity. J Clin Epidemiol 2003, 56:1163-1169.

14. Kemper HGC, Ooijendijk WTM, Stiggelbout M: Consensus over de Nederlandse Norm voor Gezond Bewegen. Tijdschrift voor Sociale Gezondheidszorg 2000, 78:180-183.

15. Alberti KG, Eckel RH, Grundy SM, Zimmet PZ, Cleeman Jl, Donato KA Fruchart JC, James WP, Loria CM, Smith SC Jr: Harmonizing the metabolic syndrome: a joint interim statement of the International Diabetes Federation Task Force on Epidemiology and Prevention; National Heart, Lung, and Blood Institute; American Heart Association; World Heart Federation; International Atherosclerosis Society; and International Association for the Study of Obesity. Circulation 2009, 120:1640-1645.

16. Lerman RH, Minich DM, Darland G, Lamb JJ, Schiltz B, Babish JG, Bland JS, Tripp ML: Enhancement of a modified Mediterranean-style, low glycemic load diet with specific phytochemicals improves cardiometabolic risk factors in subjects with metabolic syndrome and hypercholesterolemia in a randomized trial. Nutr Metab (Lond) 2008, 5:29.

17. Lundgren JD, Malcolm R, Binks M, O'Neil PM: Remission of metabolic syndrome following a 15-week low-calorie lifestyle change program for weight loss. Int J Obes (Lond) 2009, 33:144-150.

18. Salas-Salvado J, Fernandez-Ballart J, Ros E, Martinez-Gonzalez MA, Fito M, Estruch R, Corella D, Fiol M, Gomez-Gracia E, Aros F, Flores G, Lapetra J, Lamuela-Raventos R, Ruiz-Gutierrez V, Bullo M, Basora J, Covas Ml: Effect of a Mediterranean diet supplemented with nuts on metabolic syndrome status: one-year results of the PREDIMED randomized trial. Arch Intern Med 2008, 168:2449-2458.

19. Hightower KR, Olson RE, Gellish RL, Russi GD, Goslin BR, Moudgil VK: Reversal of metabolic syndrome characteristics. Metab Syndr Relat Disord 2007, 5:69-76.

20. Maxwell MS, Goslin BR, Gellish RL, Hightower KR, Olson RE, Moudgil VK, Russi GD: Metabolic syndrome status changes with fitness level change: a retrospective analysis. Metab Syndr Relat Disord 2008, 6:8-14.

21. Anderssen SA, Carroll S, Urdal P, Holme I: Combined diet and exercise intervention reverses the metabolic syndrome in middle-aged males: results from the Oslo Diet and Exercise Study. Scand J Med Sci Sports 2007, 17:687-695.

22. Lee WJ, Huang MT, Wang W, Lin CM, Chen TC, Lai IR: Effects of obesity surgery on the metabolic syndrome. Arch Surg 2004, 139:1088-1092.

23. Nugent C, Bai C, Elariny H, Gopalakrishnan P, Quigley C, Garone M Jr, Afendy M, Chan O, Wheeler A, Afendy A, Younossi ZM: Metabolic syndrome after laparoscopic bariatric surgery. Obes Surg 2008, 18:1278-1286.
24. Rossi M, da SR BF, Chaves AG Jr, Regina PF, Martin Bianco RF, Serpa NA, Zimberg CE: Remission of metabolic syndrome: a study of 140 patients six months after Roux-en-Y gastric bypass. Obes Surg 2008, 18:601-606.

25. Filippatos TD, Kiortsis DN, Liberopoulos EN, Georgoula M, Mikhailidis DP, Elisaf MS: Effect of orlistat, micronised fenofibrate and their combination on metabolic parameters in overweight and obese patients with the metabolic syndrome: the FenOrli study. Curr Med Res Opin 2005, 21:1997-2006.

26. Orchard TJ, Temprosa M, Goldberg R, Haffner S, Ratner R, Marcovina S, Fowler S: The effect of metformin and intensive lifestyle intervention on the metabolic syndrome: the Diabetes Prevention Program randomized trial. Ann Intern Med 2005, 142:611-619.

27. Bo S, Ciccone G, Baldi C, Benini L, Dusio F, Forastiere G, Lucia C, Nuti C, Durazzo M, Cassader M, Gentile L, Pagano G: Effectiveness of a lifestyle intervention on metabolic syndrome. A randomized controlled trial. J Gen Intern Med 2007, 22:1695-1703.

28. Bihan H, Takbou K, Cohen R, Michault A, Boitou F, Reach G, Le CH: Impact of short-duration lifestyle intervention in collaboration with general practitioners in patients with the metabolic syndrome. Diabetes Metab 2009, 35:185-191.

29. Onat A, Hergenc G: Low-grade inflammation, and dysfunction of highdensity lipoprotein and its apolipoproteins as a major driver of cardiometabolic risk. Metabolism 2011, 60:499-512.

30. Onat A: Metabolic syndrome: nature, therapeutic solutions and options. Expert Opin Pharmacother 2011, 12:1887-1900.

31. Burke TA, Sturkenboom MC, Lu SE, Wentworth CE, Lin Y, Rhoads GG: Discontinuation of antihypertensive drugs among newly diagnosed hypertensive patients in UK general practice. J Hypertens 2006, 24:1193-1200.

32. Tsuyuki RT, Bungard TJ: Poor adherence with hypolipidemic drugs: a lost opportunity. Pharmacotherapy 2001, 21:576-582.

33. Van Wijk BL, Klungel OH, Heerdink ER, De BA: Rate and determinants of 10-year persistence with antihypertensive drugs. J Hypertens 2005, 23:2101-2107

doi:10.1186/1471-2458-12-778

Cite this article as: den Engelsen et al:: Remission of screen-detected metabolic syndrome and its determinants: an observational study. BMC Public Health 2012 12:778.

\section{Submit your next manuscript to BioMed Central and take full advantage of:}

- Convenient online submission

- Thorough peer review

- No space constraints or color figure charges

- Immediate publication on acceptance

- Inclusion in PubMed, CAS, Scopus and Google Scholar

- Research which is freely available for redistribution 